\title{
IDENTIDADES DE GÊNERO, DIVERSIDADE SEXUAL E ENFRENTAMENTO À LGBTFOBIA NAS AULAS DE LÍNGUA INGLESA
}

\author{
Francisco Victor Macêdo Pereira ${ }^{\mathrm{i}}$ \\ José Henrique de Almeida Cavalcante ${ }^{\mathrm{ii}}$
}

\begin{abstract}
Resumo: O artigo reflete sobre as aulas de língua inglesa como espaço de questionamento das práticas de preconceitos, discriminações e violências contra a diversidade identitária de gênero e sexualidade no contexto escolar. Tendo em conta que as/os estudantes podem socializar e aprender a língua inglesa, ao mesmo tempo em que desconstroem preconceitos e violências contra a diversidade sexual e de gênero, consideramos as seguintes hipóteses de trabalho: como o inglês e o seu ensino, notadamente no contexto escolar, podem servir ao enfrentamento de práticas discriminatórias e abusivas contra as populações LGBTQIA+? Que tipos de atividades podem se inserir nas aulas de inglês, a fim de se oportunizar a desconstrução dessas práticas de abusos, discriminações e violências?
\end{abstract}

Palavras-chave: LGBTfobia na escola; Ensino/aprendizagem de língua inglesa; Enfrentamento da LGBTfobia e prática didática.

\section{GENDER IDENTITIES, SEXUAL DIVERSITY: FACING LGBTFOBIA IN ENGLISH LANGUAGE CLASSES}

\begin{abstract}
The article reflects on the English language classes as a space for questioning the practices of prejudice, discrimination and violence against gender identity diversity and sexuality in the school context. Bearing in mind that students can socialize and learn the English language, while deconstructing prejudices and violence against sexual and gender diversity, we consider the following working hypotheses: how can English and its teaching, notably in school context, serve to confront discriminatory and abusive practices against LGBTQIA + populations? What types of activities can be inserted in English classes, in order to make it possible to deconstruct these practices of abuse, discrimination and violence?
\end{abstract}

Keywords: LGBTphobia at school; English language teaching/learning; Coping with LGBTphobia and teaching practice.

\section{Introdução}

Considerando que a língua inglesa é atualmente a mais utilizada em todos os contextos comunicativos internacionais, e que os sujeitos que a dominam têm mais acesso a bens materiais, culturais e simbólicos, torna-se relevante reconhecê-la como um importante instrumento de qualificação; tanto quanto de questionamento e investigação a respeito das mais diferentes práticas e convenções sociais. Além do franqueamento de seu fluxo em praticamente 
todos os cenários - acadêmicos, institucionais, técnicos, políticos e econômicos -, o emprego da língua inglesa, em meio às mais diferentes expressões e organizações de movimentos sociais, remete igualmente ao alcance da inter e multiculturalidade: tornando os seus usuários sujeitos potencialmente mais críticos, facultando-lhes ainda o acesso mais amplo a tipos e ambientes diversos de informação, conhecimento e tecnologia.

Tendo em vista que a língua, em geral, é o espaço essencial de construção da vida social, pois somos seres do discurso que se re/constroem fundamental e simbolicamente na palavra, a comunicação e as trocas em língua inglesa tornam-se, no contexto das mídias globais, imprescindíveis: para todas/os aquelas/es que pretendem exercer a sua cidadania e mesmo a sua humanidade em perspectivas cada vez mais fluidas, amplas e cosmopolitas (MALLMANN, 2019). O trânsito da informação, ora irrestrito à descentralização das infovias, segue continuamente ressignificado pelo uso do inglês; sobretudo no que concerne à disseminação do conhecimento, à interculturalidade e à veiculação diversificada de conteúdos, por meio das mídias e plataformas digitais (MOITA LOPES, 2012).

Diante dessa realidade complexa, de fecundos desafios, incentivos e potencialidades na utilização do inglês, enquanto professores da língua, esperamos que haja sempre o engajamento dos estudantes, em seus discursos e práticas, no tocante ao compromisso com a cidadania global, o acesso e o aproveitamento socialmente responsáveis dos recursos, das tecnologias e da informação, além do seu envolvimento ético com a humanização das relações (com o meio, com os outros e consigo mesmos). Uma disposição assim, permeada pelas interfaces culturais, científicas e sociais de incidência da língua inglesa, nos concita ao compromisso de também refutar as reproduções de injustiças, desigualdades e violências: as quais têm historicamente causado a maior parcela dos sofrimentos humanos; notadamente quanto à reprodução de preconceitos e discriminações, relativos à cultura das identidades e à sua diversidade.

Lembremo-nos, sob esse aspecto, que nenhuma identidade é fixa, todas são - tal como as línguas, conformes à realidade de suas variações e situações sociais de uso - o resultado histórico de construções específicas e, por isso, estão a todo o tempo em processo de negociação, (des)construção e (trans)formação social (LOURO, 1997; BUTLER, 2010). No que diz respeito à diversidade sexual humana, as identidades de gênero e a orientação de práticas afetivas também não são fixas, não são o resultado incontrastável de nenhum determinismo genético ou biológico (MISKOLCI, 2017; COLLING, 2018). Elas são, sim, construídas socialmente, tornando-se fluidas e localizadas em sua historicidade. No sentido do que Butler (2010) nos afirma, as identidades de gênero são móveis e performáticas, sendo múltiplas e diferenciadas as suas representações corporais, imagéticas e discursivas. 
Ante a percepção disso, torna-se importante compreender as razões, as práticas, além dos expedientes socioculturais que informam essas diferentes identidades de gênero e sexualidades: consoante às dinâmicas de sua inclusão/exclusão e das violências contra si infligidas, notadamente no ambiente escolar (BENTO, 2011; MISKOLCI, 2017). Tendo em vista que a escola é o primeiro dos principais espaços de formação social, é nela onde, de maneira inquestionável, se reflete mais intensamente a dinâmica de inclusão/exclusão das produções identitárias de gênero, assim como a confluência de diversas violências e constrangimentos a ela associados (LOURO, 1997; BENTO, 2011).

Performadas e vivenciadas sob a expectação de prestígios, incitações, correções e incentivos, ademais de impactadas pelos regimes de exceções, interdições, discriminações e preconceitos, as representações subjetivas dos corpos de crianças e adolescentes, bem como as negociações em torno de suas sexualidades, desejos e vontades, se dão - no contexto escolar ainda segundo a chancela da rigidez ou do sufocamento binário de gênero (ANDRADE, 2015; MISKOLCI, 2017). No curso dos expedientes disciplinares, as produções em distinção dos corpos de meninas e meninos, da regulação a respeito do que é próprio da masculinidade em oposição à feminilidade, seguem ainda sob hirtas práticas de controle, censura e inquisição social; supostamente a título de necessidades e demandas educacionais consideradas muito sérias e urgentes.

Respaldados por saberes médicos e dispositivos jurídico-administrativos, tanto quanto por imprecações hegemônicas de ordem moral e religiosa, os parâmetros exclusivamente cis e heteronormativos predominam então na produção e adestramento dos corpos e sexualidades estudantis, devendo ser automaticamente silenciadas e apagadas todas as demais identidades e performatividades de gênero - consideradas desviantes dos padrões socialmente aceitáveis. Em vista à superação das violências e abusos sistematicamente advindos dessa matriz binária e heteronormativa de gênero, é que se torna imprescindível (re)pensar a cultura, o currículo e a própria dinâmica das práticas e saberes escolares; de modo a que as experiências de formação e convívio se deem ali de maneira mais inclusiva e sensível: a todas as pessoas, tendências, histórias, gostos e peculiaridades (próprios da diversidade humana) (BENTO, 2011; ANDRADE 2015).

A fim de que os sofrimentos e inadequações - resultantes de práticas censoras - sejam, no exercício do ensino/aprendizagem, evitados, todas/os temos de contribuir. Por isso, em evidenciação à necessidade de se garantir e valorizar uma educação mais cidadã e inclusiva, coerente com os propósitos interculturais, plurilinguísticos e multiétnicos do ensino, aprendizagem e difusão do inglês como língua franca, é que este artigo se propõe a debater o Revista Interinstitucional Artes de Educar. Rio de Janeiro, V. 7, N. 1 - pág. 293-314 janeiroabril de 2021: "Pedagogias Vitais: Corpo, Desejo e Educação" DOI: 10.12957/riae.2021.54781 


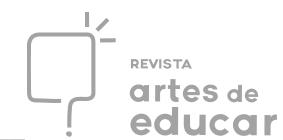

enfrentamento da LGBTfobia, na escola e na sociedade. Mediante proposições curriculares e práticas de ensino e aprendizagem - comprometidas com a afirmação das diferentes sexualidades e identidades de gênero -, o nosso escopo se volta, nas aulas de inglês, a possibilitar o diálogo com a diversidade: reconhecendo-a e valorizando-a, em condições de igualdade (MOITA LOPES, 2002); na perspectiva dos direitos fundamentais, da liberdade, da dignidade, autodeterminação e cidadania global de todas as pessoas.

Como preâmbulo a isso, abordamos alguns aspectos a pretexto da construção histórica das identidades de gênero e da diversidade sexual. Na sequência é que, então, explicitamos algumas relações dessas identidades e sexualidades com propostas de ensino/aprendizagem da língua inglesa; de modo a descrevermos a sugestão de uma atividade para o seu ensino sem mais reproduções de estereótipos, desigualdades e violências simbólicas de gênero. Por último, apresentamos as considerações finais; nas quais retomamos, com os subsídios de nossas formulações, o questionamento a propósito das hipóteses apresentadas: quanto ao engajamento do ensino de inglês no enfrentamento a práticas discriminatórias e abusivas contra as populações LGBTQIA+, notadamente no contexto escolar.

\section{Reflexões sobre as aulas de língua inglesa no enfrentamento da lgbtfobia: desafios e possibilidades no contexto escolar}

\section{A propósito da construção histórica das identidades de gênero e da diversidade sexual}

No que toca às sexualidades, às suas práticas e ao uso econômico dos corpos e dos sexos, as identidades de gênero - posto que compulsoriamente moduladas entre as masculinidades e/ou as feminilidades - seguem circunstanciadas às produções socioculturais das vontades e interesses dos/sobre os sujeitos, as suas corporeidades e os controles ao aproveitamento de sua vitalidade. As distintas outorgas - à conta do biologismo moderno - remetem tais identidades à determinação de papéis e dissipações funcionais de poderes, prestígios, direitos e deveres; administrados também em conformação às convenções e lugares de gênero.

As contingências morais, culturais e econômicas sob as quais são infundidas e disseminadas as representações e percepções imagéticas - a propósito dessas identidades binárias - são, a despeito de mantidas em irredutíveis oposições entre masculinidades e feminilidades, simbolicamente fluidas e relativas: em derivações móveis e constantes a um espectro muito amplo de fatores, gradientes corporais e composicionais de aferição ao longo da Revista Interinstitucional Artes de Educar. Rio de Janeiro, V. 7, N. 1 - pág. 293-314 janeiroabril de 2021: "Pedagogias Vitais: Corpo, Desejo e Educação" DOI: 10.12957/riae.2021.54781 
história (BUTLER, 2010; COLLING, 2018). Em outras palavras, em todos os lugares, não se é homem ou mulher - ou o que quer que de um desses dois parâmetros mais ou menos se afaste ou se aproxime - precisamente da mesma forma, nem de acordo com as mesmas e exatas regras, condições e exigências; supostamente iguais e inalteradas desde que o mundo é mundo ou desde que todas as coisas foram criadas ou ditas em sua origem ou princípio, sem quaisquer mudanças essenciais até o tempo presente.

Os sujeitos tornam-se, na verdade, homens ou mulheres muito mais pela impressão das produções e tecnologias de gênero - as quais lhes são, desde a mais tenra infância, localmente dispostas e introjetadas sobre os seus corpos e mentes - do que propriamente pelo órgão segundo o qual se lhes é assignado, ao nascer, este ou aqueloutro sexo; ou ainda pela quantidade de hormônios que as suas gônadas e demais glândulas endócrinas particularmente segreguem (BEAUVOIR, 1970; BUTLER, 2010). Geneticamente, ou melhor, cromossomicamente, é possível que se determine se um indivíduo é macho ou fêmea; no entanto, mesmo as disposições biológicas, fisiológicas e hormonais - advindas dessa marca ou inscrição genética - variam substancialmente em meio às inúmeras induções biopsíquicas e socioeconômicas de produção do gênero (COLLING, 2018).

A isso equivale dizer que, grosso modo, nem mesmo naquilo que corresponde à percepção ou à leitura de gênero - segundo a natureza ou a biologia dos corpos - pode haver determinações absolutas: quanto ao que taxativamente confira as masculinidades ou as feminilidades dos sujeitos. Assim, a despeito do sexo biológico e do conjunto de características sexuais secundárias e/ou atávicas, haverá sempre muitas e variadas exceções quanto ao que se espera do ser homem e do ser mulher, bem como à conformação biopsíquica e social das suas identidades de gênero.

As identidades de gênero não são, portanto, propriedade dos indivíduos nem resultado indefectível de seus genomas, mas sim construções culturais e subjetivas: concebidas em conformação normativa a padrões os quais socialmente nos forjam e orientam. Por mais que estejam naturalizadas as hierarquias e cristalizadas as assinaturas de privilégios, as assimetrias sociais entre homens, brancos, heterossexuais sobre todas as demais identidades de classe, raça, gênero e sexualidade não podem ser vistas como determinações de ordem absoluta; são antes o efeito ou o resultado histórico do assentamento de múltiplos dispositivos de poderes (morais, políticos, econômicos, tecnológicos). Embora pensadas como identidades sólidas, permanentes, de referência natural e científica, as distinções que essencialmente graduam e opõem homens a mulheres, brancos a não-brancos e ricos a pobres não se dão como beneplácito divino, por 
distinção de sua variação à dominância ou por sua superioridade como destinação; tampouco como consequência de qualquer inferioridade de uns corpos em subjugação aos demais.

A hegemonia ou a primazia das identidades masculinas, brancas e heterocentradas tem, contudo, produzido a subalternização, a exclusão e/ou a sub-representação sistemática de todas as demais; sobretudo quanto à dispensação dos efeitos e controle dos dispositivos de poderes. O desenho epistemológico dessa dominação deita as suas raízes justamente sobre o chão da escola, local onde a ordem de diversos dos discursos de dominação é apresentada conforme os preceitos sociais de normalidade, moralidade e cientificidade. Importa, então, considerar a necessidade de não se promover mais, no ambiente escolar, situações de hierarquização identitária; uma vez que as/os estudantes observam e internalizam as disposições do espaço, da instituição e do trabalho escolar e pedagógico como própria assimilação do mundo: tanto quanto as atitudes, ações, reações, valores e comportamentos de vida - traduzidos no currículo das diretrizes e conteúdos, mas também nas tendências de posturas e condutas de docentes, gestores/as, orientadores/as e coordenadores/as pedagógicos/as.

Em decorrência disso, lidar de maneira inclusiva e respeitosa com as múltiplas identidades de gênero e a diversidade sexual, ao invés de estigmatizá-las e relegá-las ao apagamento, à exclusão, senão propriamente à perseguição, não é uma tarefa fácil, posto que absolutamente urgente e necessária. Há ainda de se atentar para o fato de que as crianças já chegam à escola constituídas pelas bases morais familiares, cabendo às/aos educadores/as legitimá-las ou relativizá-las, corroborando ou não - no sentindo de desconstruir ou afirmar certas atitudes de preconceitos, violências, machismos e LGBTfobias. Essa situação faz com que as práticas pedagógicas e curriculares, no tratamento das diferenças de gênero e sexualidades, sejam ainda muito polêmicas, complexas e desconfortáveis no contexto escolar brasileiro. Toda a sua temática segue ainda como tabu (BENTO, 2011; PINTO, 2014); senão tratada, na maioria das vezes, de forma superficial, descuidada, estereotipada e essencializada.

Não obstante a isso, a resistência a todas as opressões de gênero e violências da cultura machista e LGBTfóbica vem se firmando: em tentativas francas e corajosas à construção de uma sociedade mais inclusiva, acolhedora e democrática; na qual as diferenças sejam vistas e compreendidas como fonte de enriquecimento social, e não como causa de sofrimento, violência e exclusão para as minorias (BENTO, 2011; ANDRADE, 2015; PINTO, 2014). Ainda assim, principalmente os meninos que se afastam dos modelos da masculinidade tóxica, hegemônica e opressora das mulheres e minorias sexuais, seguem vistos como desviados, aberrações; sendo evitados como aqueles que renegam o privilégio de ser macho. São-lhes atribuídos - ainda hoje - os diagnósticos de diversas fraquezas e doenças, de ordem psíquica, Revista Interinstitucional Artes de Educar. Rio de Janeiro, V. 7, N. 1 - pág. 293-314 janeiroabril de 2021: "Pedagogias Vitais: Corpo, Desejo e Educação" DOI: 10.12957/riae.2021.54781 


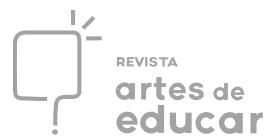

moral e fisiológica; além de experimentarem múltiplas práticas de discriminação e subalternização no contexto escolar (LOURO, 1997; MISKOLCI, 2017), as quais, algumas vezes, resultam fatais.

À vista disso, as diferentes identidades de gênero e sexualidades - ademais das de gays, também as de lésbicas, bissexuais, travestis, mulheres e homens transexuais - não podem mais seguir renegadas, apagadas ou invisibilizadas: têm de ser vistas e compreendidas na escola como construções socioculturais legítimas e saudáveis da diversidade sexual humana (LOURO, 2000; BUTLER, 2010; BENTO, 2011); mediante as quais se realizam diferentes maneiras e possibilidades de se ser mulher e de se ser homem em sociedade. É importante entender que "homem e masculino podem significar tanto um corpo feminino como um masculino, e mulher e feminino, tanto um corpo masculino como um feminino" (BUTLER, 2010, p. 24). Todavia, como dissemos, essa compreensão segue longe de ser bem aceita, resultando muitas vezes em violências institucionais à autodeterminação de corpos e sexualidades. Prevalecem ainda os sistemas de cerceamento, punição e mesmo de eliminação de todos os sujeitos que destoam ou fogem às regras convencionais de normalidade.

As tentativas de encerramento institucional das performances de feminilidade em corpos biológicos de fêmeas e das de masculinidade em de machos representam, no entanto - sobretudo para as pessoas transexuais -, uma verdadeira violência: a qual lhes custa, não raro, o preço da própria vida (ANDRADE, 2015). O que a educação para a liberdade e o respeito à diversidade deve nos propiciar é, pois, o questionamento crítico sobre como nos são introjetadas as formas de se ser e de se ver sexualmente (n)o/(n)a outro/a: para a preservação de vidas e o cultivo de mais solidariedade. Importa o (re)conhecimento reflexivo de nossa própria subjetividade em relações mais amplas, humanizadas e sensíveis; com menos ódios e violências (BENTO, 2011).

Que aprendamos, pois, a perceber e apreciar as diferenças todas; sem compará-las nem classificá-las por critérios ou acusações elitistas, racistas, misóginas e/ou LGBTfóbicas; hierarquizando ou subjugando as identidades de gênero, raça e sexualidade a partir de visões e comportamentos que normatizam e reproduzem tantas violências, opressões, explorações e exclusões. Que aprendamos também a tratar e respeitar as diferenças conforme as suas especificidades, histórias, trajetórias e experiências de vida; nunca de modo injusto ou desigual, a lhes infligir ainda mais violências e preconceitos.

Do que disso se segue, deve-se reforçar a importância de um currículo segundo o qual se concebam processos e práticas de ensino/aprendizagem fundamentados no reconhecimento, afirmação e respeito das diferenças em meio à diversidade humana; com o objetivo de atingir, integralmente, todas/os as/os estudantes (BENTO, 2011; MISKOLCI, 2017). Ou seja, um Revista Interinstitucional Artes de Educar. Rio de Janeiro, V. 7, N. 1 - pág. 293-314 janeiroabril de 2021: "Pedagogias Vitais: Corpo, Desejo e Educação" DOI: 10.12957/riae.2021.54781 
currículo voltado para a ampla formação científica e humana; por intermédio do qual todas as pessoas sejam incluídas e educadas para o respeito às diferenças - a todas as diferenças! Nesse intuito, o ensino/aprendizagem de língua inglesa, com foco na interculturalidade, no plurilinguismo, na multietnicidade e voltado ao escopo da formação para a cidadania plena, plural e global, deve ser pensado - especificamente no contexto escolar - como ferramenta educacional imprescindível ao enfrentamento de todas as formas de violências: de acordo com o oferecimento de oportunidades educacionais, profissionais e comunicativas mais amplas, voltadas ao ideal de uma sociedade mais justa, humana e igualitária (MALLMANN, 2019).

\section{As identidades de gênero e a diversidade sexual ante os desafios de ensino e aprendizagem da língua inglesa}

Considerando que a língua e a linguagem não são jamais neutras e que as práticas discursivas envolvem escolhas ideológicas e políticas estrategicamente atravessadas por inúmeras relações e disputas de poder - com múltiplos efeitos no mundo social (LOURO, 2013; BRASIL, 2017) -, é fundamental que se reflita sobre os modos como se ensina a língua; como se concebem a comunicação e a expressão nos diferentes contextos e propósitos educacionais; bem como se observe as maneiras como a própria linguagem é utilizada em sala de aula, nas distintas situações de aprendizagem, inclusive nos materiais didáticos.

Infelizmente, muitos discursos em situações de ensino/aprendizagem atuam ainda no sentido de corroborar a naturalização de preconceitos e estereótipos, reforçando - e até normalizando - violências, constrangimentos e sofrimentos: os quais seguem reproduzidos sobre as vidas e os corpos de sujeitos presentes no espaço escolar. São opressões, supressões, injustiças e desigualdades de gênero, mas também relativas a preconceitos e discriminações etnicorraciais, de origem e classe social. O enfrentamento a essas situações de constrangimento e violência no contexto da escola pode encontrar, nas aulas de língua, um aliado importante: para a conscientização sobre a necessidade de se reconhecer e se valorizar a diversidade, assim como de se respeitar os direitos humanos; contribuindo para o questionamento e a desconstrução dos privilégios de algumas identidades e posições sociais em detrimento de outras.

A propósito disso, para Pennycook (2006), os estudos que envolvem língua, linguagem e gênero não devem ser relacionados meramente aos registros e/ou à percepção de como homens e mulheres falam ou articulam - de modos diferentes - os seus discursos: como se as 
condições de se ser ele ou ela preexistissem, qual categorias absolutas e inalteradas de identidade, aos usos sociais da língua pelos/as falantes. Ao invés disso, deve-se compreender como as pessoas desempenham socialmente o gênero, precisamente mediante o uso das palavras e as escolhas de estratégias e estruturas: na articulação dos discursos em formulação de seus valores, necessidades e interesses. Isso não quer dizer que sejam constantemente desempenhadas identidades generificadas por meio da linguagem; mas, antes, que construímos ou reforçamos - também por meio dela - identidades e performatividades de gênero: as quais nos são socialmente induzidas e expectadas, ao mesmo tempo em que intermediadas, nas negociações com nossos/as interlocutores/as.

Afinal, buscamos falar e/ou nos expressar linguisticamente conforme as demandas que nos são social e culturalmente geradas: também no que concerne à percepção mais ou menos masculina ou feminina da apresentação e confirmação de nossos corpos. Portanto, para além das demais composições de gênero, o desempenho discursivo é igualmente um fator valioso à demarcação intersubjetiva de nossas identidades e/ou performances de gênero. Do que disso se segue, é importante compreender que, a pretexto da repetição de padrões discursivos, a linguagem se transforma em verdade, identidade e/ou marca distintiva dos sujeitos: associadas concorrentemente à impressão reiterada e interseccionada de determinadas outras performatividades (corporais e sociais) (PENNYCOOK, 2006).

Compreendidos os recorrentes modos por meio dos quais enunciam e se apropriam preferencialmente de uns, e não de outros atos e estilos de fala, e de como os veiculam eficientemente em suas marcas e assinaturas discursivas, homens e mulheres - afora à indelével urdidura das marcas de feminilidades e/ou masculinidades - representam, performam e materializam, para além de seus corpos, também na articulação cotidiana de seus discursos, as suas identidades: às quais, por último, se injungem inúmeros preconceitos e estereótipos de gênero. As verdades ou as características a pretexto dessas marcas discursivas - nas falas e expressões dos sujeitos - são carreadas, portanto, em conformidade com a expectativa das performances de gênero; reproduzindo, por sua conta, também inúmeras delimitações e preconceitos de ordem linguística (LOURO, 2013).

De fato, tais marcas ou assinaturas discursivas de gênero são facilmente observáveis em enunciados como "menino que fala fino vira bicha" ou "menina que fala palavrão fica feia" ou "menino que chora é marica" ou "fale como um homem" ou ainda "só podia ser mulher pra falar essas besteiras”. Diga-se que tais admoestações preconceituosas - de bases discursivas machistas e misóginas - são enunciadas de modo reiterado justamente no contexto da escola (PINTO, 2014). Diante disso, é preciso, ademais de cuidar da linguagem empregada no Revista Interinstitucional Artes de Educar. Rio de Janeiro, V. 7, N. 1 - pág. 293-314 janeiroabril de 2021: "Pedagogias Vitais: Corpo, Desejo e Educação" DOI: 10.12957/riae.2021.54781 
cotidiano dos ambientes e situações educacionais, igualmente politizar as estruturas e os conteúdos incoerentemente reproduzidos em sequências e materiais didáticos; em específico no que repliquem ordens, desvalores e posições sociais repletas de estereótipos e preconceitos de gênero - de efeitos machistas, misóginos e LGBTfóbicos.

Talvez a maioria das pessoas ainda olhe com desconfiança, desdém e mesmo com menosprezo as políticas linguísticas que se esforçam por minimizar, nos atos de fala e nas produções textuais, as desigualdades e opressões discursivas de gênero. Modalizar a linguagem, buscar neutralizar as marcas de gênero nos enunciados gerais, instrutivos e institucionais, priorizar escolhas semânticas, morfológicas e sintáticas as quais não reproduzam estereótipos, hierarquias ou preconceitos de gênero são, contudo, atitudes muito mais importantes do que o que se pode, à primeira vista, imaginar (LOURO, 2013). Temos de atentar, além disso, para o fato de que tais opressões de gênero, entranhadas no cotidiano de nossos discursos e nas formas e usos - tanto tradicionais quanto corriqueiros - da língua e da linguagem, respondem também pelo horror de muitas das violências, todos os dias presenciadas no contexto da escola. Sistemática e silenciosamente, é da escola que é expulsa a maioria das/os estudantes LGBTQIA+ (ANDRADE, 2015). Os altíssimos índices de suicídio de crianças e adolescentes têm, ademais, como uma de suas principais causas as LGBTfobias ali sofridas.

É igualmente na escola onde primeiro se normalizam, não só os preconceitos e discriminações LGBTfóbicas, como também as agressões e violências - as quais ora têm feito do Brasil o país onde está em curso um verdadeiro extermínio de mulheres travestis e transexuais; ademais dos absurdos índices de estupros, feminicídios e violências de gênero de todo o tipo... todos os dias, todas as horas, em todas as classes e circunstâncias sociais, contra as mulheres e as minorias sexuais ${ }^{\text {iii. }}$ Torna-se, por isso, indispensável a politização da igualdade de gênero nos cotidianos escolares: não apenas na sala de aula, como também na sala das/os professoras/es, nas reuniões pedagógicas e de planejamento, junto à comunidade, nos treinamentos e formações e em todas as demais situações inerentes ao trabalho pedagógico e escolar (BENTO, 2011; LOURO, 2013).

Interessa ainda saber quem, nessas ocasiões, preponderantemente fala? A quem se costuma dar ouvidos? Quais falas são comumente referenciadas/reverenciadas? Quais são sempre desacreditadas, desautorizadas e ironizadas? A quem é mais conferida e de quem é mais cassada a palavra? As dissensões de gênero são, seguramente, uma chave para a resposta de todas essas questões e, no sentido em que conferem o diagnóstico de distorções, injustiças, desigualdades, preconceitos, concussões, abusos e agressões machistas, misóginas e 
LGBTfóbicas, elas devem estar invariavelmente em pauta: a fim de que conscientemente se busque, no contexto escolar, o enfrentamento de todos os seus estragos e prejuízos.

Na compreensão dessa necessidade, faz-se igualmente importante a ênfase na educação que reconheça o papel da língua adicional para a construção de um mundo socialmente mais justo, solidário e com mais oportunidades para pessoas LGBTQIA+, mulheres, negras e trabalhadoras (PINTO, 2014). Como evidenciação disso, o ensino de inglês deve - cada vez mais - se descolar dos aspectos linguísticos meramente gramaticais; quase sempre sem nenhum eco com o enfrentamento dos desafios e problemas da realidade das/os estudantes (MALLMANN, 2019). Com efeito, o engessamento aos aspectos formais da língua, o ensino da língua pela língua, além de tornar as aulas monótonas e pouco produtivas, não colabora em nada à ultrapassagem das barreiras de estereótipos e preconceitos: opostos, de maneira estrutural e sistemática, às identidades socialmente subalternizadas.

Infelizmente, em suas formas e usos hegemônicos, o ensino da língua se mantém - em nossa realidade - sob os pressupostos e ênfases de prestígios, hierarquias e privilégios sociais. Além de reduzido a inautênticas propostas técnicas ou instrumentais, acrescem-se - comumente ao ensino de inglês no Brasil - os arremedos etnocentristas e as pantomimas de didatismos norte-americanos: algo, a nosso ver, profundamente prejudicial, e que precisa ser reconfigurado em favor de concepções de maior apreço e respeito às diversidades locais e aos direitos humanos. Referimo-nos à verificação da disposição de ensino, segundo a atual BNCC (2017), em consonância ao papel que lhe é assinalado - ao inglês - como língua adicional: de integração intercultural, multiétnica e multirreferenciada; na indução de sua disponibilização como língua franca e de acesso à cidadania global. Diga-se que essa noção de língua franca pauta-se justamente na perspectiva de superação de todos os reveses hegemônicos, para além das históricas imposições da cultura e do imperialismo norte-americanos. Ao arrepio disso, devese disseminar a propensão comunicativa da língua: através de sua utilização nos mais diversos contextos de culturas, etnias, nacionalidades, expressões, tecnologias e referências sociais; sempre na confluência de seu potencial à projeção da cidadania global (MALLMANN, 2019).

Ainda assim, talvez se possa invocar - malgrado essa asserção - a inerente precariedade do ensino de inglês no contexto escolar brasileiro, sobretudo na rede pública: muito aquém de proporcionar às/aos nossas/os estudantes o alcance do ideal de língua em sua dimensão franca e internacional. Entretanto, a despeito de quaisquer pessimismos, a disseminação do inglês impõe-se crescentemente ao cotidiano de todas as nossas crianças e adolescentes, incluídas as das periferias e redes oficiais de ensino: por meio do uso proeminente de mídias e plataformas digitais de músicas, jogos, vídeos e redes sociais. Nesse cenário, o internamento peremptório Revista Interinstitucional Artes de Educar. Rio de Janeiro, V. 7, N. 1 - pág. 293-314 janeiroabril de 2021: "Pedagogias Vitais: Corpo, Desejo e Educação" DOI: 10.12957/ riae.2021.54781 
no mundo da web, das mídias e tecnologias digitais pode e deve ser positivamente explorado para a superação das precariedades - de recursos, mas também de violências e marginalizações - no ensino da língua em nossas escolas públicas e privadas. De fato, é como se não houvesse barreiras linguísticas para o manuseio, a apropriação e o compartilhamento de diferentes conteúdos e plataformas virtuais em inglês; como o spotify, o instagram, o facebook e o youtube. Isso grosso modo confirma, por parte de nossas/os estudantes, a inserção do inglês nos termos de uma língua franca, tal como disposto pela BNCC (2017).

Inobstante a sua irrefreável difusão - por meio das ferramentas e interfaces digitais -, o que nos interessa pontuar é que, sob o enfoque dos usos prescritos pelo ensino, pela gramática e demais formas privilegiadas, persiste - nas propostas do inglês como língua adicional - o predomínio de diversos elitismos e hierarquias linguístico-sociais. Sob esse aspecto, a insistência ou a preferência pela utilização dos designativos do gênero masculino é o que mais nos preocupa e desconcerta. Apesar de as flexões de gênero serem menos marcadas do que, por exemplo, na língua portuguesa, no inglês não há muita diferença. Em consequência disso, as concepções didáticas em torno do ensino da língua demonstram o quanto se segue corroborando, instituindo e demarcando os lugares sociais de classe e gênero. Diga-se que, na língua inglesa, isso não se dá apenas com o apagamento do feminino - algo menos explícito do que é, como dissemos, no português e nas demais línguas latinas -, mas também pela escolha de adjetivos para diferenciar o feminino do masculino, pelo uso (ou não) de diminutivos, o emprego de hipocorísticos para efeitos de infantilização e desautorização da presença e atuação discursiva - das mulheres e minorias - nas diferentes situações interativas e comunicacionais. Isso se verifica também na escolha de verbos, nas associações e analogias entre determinadas qualidades, atributos ou comportamentos; principalmente no que concernem às identidades de raça, gênero e sexualidade.

Decerto que, no ensino de língua e linguagem, nossas práticas discursivas não distinguem, de forma isenta, as assinações ou os lugares de poder (LOURO, 2013); elas, antes, os denominam, conceituam, delimitam, os instituem: não apenas à cata das disposições curriculares, mas igualmente produzindo e fixando - por suas variações - diferenças significativas entre os sujeitos, os seus interesses, as substâncias e marcas de suas disputas e identidades. Por isso, através das práticas discursivas, igualmente se excluem e se confirmam de forma naturalizada (e quase imperceptível) - vários desvios hierárquicos, inúmeras supressões e opressões de gênero, no destaque de usos e repetições impositivos: diante dos quais a detecção e a oposição de resistências são quase sempre dificultadas. 
É preciso, à revelia disso, reconhecer que os diferentes sujeitos usam a língua a partir de suas próprias contingências sociais e experiências de vida - especificamente como homens, mulheres, gays, lésbicas, travestis, transexuais, negras/os, periféricas/os; ao mesmo tempo em que, nessas práticas, elas/es se (re)constroem e se reinventam, interagindo - uns/umas com os/as outros/as - por meio da linguagem. Destituir-lhes das suas diferenças ante a imposição de formas linguísticas e discursivas engessadas e/ou autoritárias é, portanto, o mesmo que lhes negar a vida e a liberdade (MOITA LOPES, 2003).

Diante disso, Furlani (2013) nos sugere que, tanto nas produções orais quanto nas escritas, em qualquer nível de ensino, é aconselhável o esforço estratégico de se evitar - tanto quanto possível - o tratamento exclusivo no masculino; ou a designação a cargos e funções de prestígio exclusivamente no gênero masculino; bem como se atente para a linguagem presente nos livros didáticos, que costumeiramente também privilegia apenas o uso do masculino. É importante, enfim, nos ocuparmos na criação de cada vez mais possibilidades, espaços e visibilidades comunicativas e identitárias; não apenas no âmbito discursivo, mas também da materialização política de acessos e oportunidades - de modo a que mulheres, homens, negras/os, gays, lésbicas, travestis, transexuais, bissexuais e demais identidades sejam todas incluídas socialmente, sobretudo no ambiente escolar.

Por isso, nós, professoras/es de língua inglesa, não podemos nos limitar a ensinar apenas a língua pela língua; muito pelo contrário, temos de nos propor a dialogar com a mais ampla diversidade de pessoas e culturas, com as suas diferentes práticas socioculturais: mediante as quais elas interagem no enfrentamento de seus desafios e na agência de suas potências de vida. Para tanto, é preciso questionar os discursos e as práticas que, muitas vezes, estão cristalizados nos preconceitos de gênero, internados nas estruturas privilegiadas de usos, atos e produções linguísticas; persistindo estampados em muitas das propostas desavisadas de materiais e sequências didáticas - ainda a serviço da replicação dos efeitos de injustiças, desigualdades e violências de gênero.

Na prática, a linguagem se traduz como a própria vida em interação discursiva, e somos todas/os sujeitos dos discursos que se (re)constroem vitalmente por meio do uso da língua. Aprendemos, pois, a ser nos encontros mediados pelas palavras (MOITA LOPES, 2003): as mesmas que são matéria prima das aulas de língua. As palavras têm, com efeito, o poder de redimensionar qualquer sofrimento humano; nomeá-lo, denunciá-lo e indigitar os seus responsáveis. Dessa forma, uma educação cidadã e mais inclusiva há de se construir igualmente por intermédio das aulas de inglês; as quais devem ser convertidas em espaço para a promoção da igualdade de gênero e diversidade sexual, assim como de outros temas de relevância social: Revista Interinstitucional Artes de Educar. Rio de Janeiro, V. 7, N. 1 - pág. 293-314 janeiroabril de 2021: "Pedagogias Vitais: Corpo, Desejo e Educação" DOI: 10.12957/riae.2021.54781 
com o intuito de contribuírem à superação de tudo o que nos perturba, violenta e exclui, tanto no ambiente escolar como na sociedade em geral.

\section{Anti-LGBTfobia nas aulas de língua inglesa}

Dissemos que os temas, conteúdos e abordagens curriculares - transversais a todos os componentes e propostas didáticas, dos diferentes níveis e modalidades de ensino - devem proporcionar as discussões concernentes à igualdade de gênero e à diversidade sexual; conforme critérios os quais contemplem a afirmação das diferentes identidades, performances e corporeidades - em condições de justiça, igualdade e cidadania plenas (BENTO, 2011). Dissemos, ademais, que à escola cabe a promoção da cidadania, do respeito e a defesa da vida; bem como assegurar a liberdade, a dignidade e a diversidade de todas as pessoas: conforme as suas distintas maneiras de ser e os modos não hegemônicos de vivenciarem as suas sexualidades, construções e performances de gênero (LOURO, 2000; BENTO, 2011; MISKOLCI, 2017).

Conforme esse entendimento, também as aulas de língua inglesa, no que atinem ao seu escopo comunicativo e de formação à cidadania global, devem conceber em seus objetivos, no desenvolvimento de suas estratégias e procedimentos, a abordagem dos conteúdos linguísticos e aspectos discursivos condizentes à promoção dos direitos humanos e da diversidade: concorrendo - em ambiente multiétnico, plurilinguístico e intercultural - para o enfrentamento das LGBTfobias e demais violências de gênero (ainda amplamente incidentes, tanto no cotidiano escolar, quanto na vida social das/os estudantes).

Há de se, então, conceber sequências e propostas didáticas as quais contribuam com a familiarização de todas/os as/os alunas/os - de modo respeitoso, inclusivo e democrático - com a diversidade sexual e de gênero; com o intuito de, sobretudo, despatologizar, desagravar e descriminalizar as condutas, performances, identidades e orientações afetivas das homossexualidades, transexualidades, bissexualidades, intersexualidades e não-binarismos queer - sobre os quais ainda recaem complexos sistemas de condenações, culpas, inquisições, discriminações, ódios sociais, injunções hipócritas, além de inúmeras imprecações e perseguições de ordem moral e religiosa (BUTLER, 2011; MISKOLCI, 2017).

Para além da promoção de sua cidadania, conferir visibilidade e protagonismo às/aos estudantes LGBTQIA+ - nos contextos da escola e das aulas de inglês - é outro aspecto de fundamental importância; no sentido de que lhes sejam assegurados a representatividade, a Revista Interinstitucional Artes de Educar. Rio de Janeiro, V. 7, N. 1 - pág. 293-314 janeiroabril de 2021: "Pedagogias Vitais: Corpo, Desejo e Educação" DOI: 10.12957/riae.2021.54781 
criticidade, a autonomia e o fortalecimento (cognitivo, psíquico e emocional) - imprescindíveis ao enfrentamento das múltiplas violências e hostilidades às quais estão invariavelmente expostas/os, e contra as quais têm de resistir (ANDRADE, 2015). Outro aspecto importante é o de altear a crítica aos padrões da hegemonia hétero-cisnormativa, como medida em contenção à propagação de violências, opressões, discriminações, ódios, abusos e preconceitos contra as pessoas LGBTQIA+ (BENTO, 2011).

Vê-se, diante disso, que os desafios são imensos, e pergunta-se: como é possível que o ensino e a aprendizagem de inglês contribuam, no contexto escolar, à resistência das atuações contra as LGBTfobias? Abordar as temáticas de gênero e diversidade sexual com desenvoltura e comprometimento, em defesa da vida e da liberdade, é certamente o primeiro passo. De fato, não deve haver nenhum impedimento nem constrangimento em se falar, também nas aulas de inglês, sobre as diferentes identidades de gênero e sexualidades; tampouco em abertamente se condenar os horrores, os crimes e as injustiças ocasionados - todos os dias, nas mais diversas situações - pelas violências, agressões, abusos e ódios LGBTfóbicos.

Esclarecer quanto às causas e consequências sociais dos privilégios cisheteronormativos e denunciar as LGBTfobias no próprio meio escolar é igualmente muito relevante. Além disso, transmitir segurança e incentivo - mediante informações confiáveis, de redes nacionais e internacionais de apoio no combate ao ódio e à ignorância - é também eficaz para impulsar a representatividade, a autonomia e o protagonismo das/os estudantes LGBTQIA+: a fim de valorizá-las/os e fortalecê-las/os para o enfrentamento de todas as violências e opressões, das quais são alvos recorrentes e/ou estruturais.

Não noutro sentido, potencializar as discussões de gênero por meio da projeção da língua inglesa torna-se uma estratégia relevante, no sentido de se perceber a diversidade sexual e os desafios de sua compreensão como uma realidade extensiva a todos os povos e culturas. Expandir o contato das/os estudantes LGBTQIA+ com instituições de apoio e solidariedade internacional, no concurso do fortalecimento de sua autoestima e consciência crítica, é igualmente louvável. Atitudes positivas, de empoderamento e capacitação - mediante a utilização/aquisição da língua franca internacional -, podem, enfim, colaborar decisivamente na melhoria da confiança dessas/es estudantes: fazendo-lhes entender - bem como a todas/os as/os demais - que não há mal algum, não é anormal, pecaminoso nem doentio, em nenhum lugar do mundo, ser LGBTQIA+; e sim que os problemas quanto a isso consistem nas violências, agressões e abusos os quais são infligidos e replicados contra essas pessoas, precisamente em espaços e contextos como o da escola. 
Tais atitudes positivas em relação às pessoas LGBTQIA+ devem, enfim, fazer parte do compromisso político, social e humanitário da escola; havendo de estar previstas em seu Projeto Político Pedagógico, bem como em suas diretrizes, práticas e metas educacionais. Decerto que a seriedade quanto à verificação disso já contribuiria enormemente para a diminuição dos alarmantes índices de suicídio entre jovens e crianças LGBTQIA+, tanto quanto minimizaria a expulsão compulsória a que são submetidas/os na maioria dos contextos escolares (ANDRADE, 2015; MISKOLCI, 2017): onde ainda excedem os machismos, as misoginias, as LGBTfobias e as produções sistemáticas e inconsequentes de suas violências ${ }^{\text {iv. }}$

Importante, afinal, que se confira visibilidade a todas as diversas identidades e sexualidades também nas propostas de trabalho e formação comunicativa com a língua inglesa; as quais têm de contemplar, conforme disposição da BNCC (2017), os princípios da multietnicidade, da diversidade e da interculturalidade: no intuito da formação para a democracia, o apreço às diferenças e a cidadania global. Na intenção, pois, de contribuir para que as pessoas LGBTQIA+ sejam tratadas com a mesma dignidade dos sujeitos cis e heterocentrados, sugerimos para as aulas de inglês do Ensino Médio e/ou Fundamental II (público alvo de estudantes entre 13 e 17 anos) a abordagem temática dos preconceitos de gênero e sexualidade, mediante a promoção de sequências de brainstormings, fóruns e/ou debates próprios.

De maneira específica, seguida de um brainstorming acerca do que as/os estudantes pensam sobre diversidade sexual e identidade de gênero, a proposta gira em torno da exibição de alguns vídeos do youtube (mais precisamente dos que estão na comunidade do React channel $^{\nu}$ ); de modo a suscitar a interação da turma em debates conduzidos pela/o professor/a de inglês. A ideia é a de que os/as alunos/as compartilhem as suas impressões, opiniões e argumentos sobre a forma como - nos vídeos - as crianças norte-americanas, de diferentes etnias e classes sociais, reagem a situações comuns que lhes são apresentadas: de cenas, eventos, episódios e animações em que são retratadas a sociabilidade, a celebração e a demonstração de afeto entre pessoas LGBTQIA+.

As situações dos vídeos são as mais comuns: pedidos de casamento, demonstrações públicas de carinho, celebrações, cerimônias, festividades, enamoramentos... A diferença é que, em todas elas, ao invés de pessoas cis e heterocentradas, estão figurando/atuando pessoas ou personagens LGBTQIA+. O intuito das produções do canal é o de suscitar - de modo franco, aberto e descontraído - a reflexão a propósito da diversidade sexual e de gênero. Afinal, o que haveria de estranho, inusitado, errado ou inadequado nesses vídeos, além do fato de as pessoas ou personagens ali serem lésbicas, gays e/ou transexuais? 


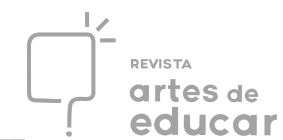

Dentre os vídeos do canal, alguns são mais interessantes para propostas de trabalho e/ou discussões de gênero em aulas de inglês: Kids react! In a heartbeat ${ }^{\nu i}$, Kids react to gay marriage ruling ${ }^{\text {vii }}$, entre outros. No entanto, de todos esses, um nos parece mais acertado para o início de nossa proposta de debates como sequência didática: Kids react to gay marriage . ${ }^{\text {viii }}$

Nesse vídeo, treze crianças, entre sete e doze anos, são apresentadas, separadamente, a duas cenas de pedidos de casamento, de dois casais de noivas/os: um de homens gays e outro de lésbicas. Os registros são de comoção, alegria, surpresa, entusiasmo, festa e muita emoção; com trocas de beijos, abraços, lágrimas, sorrisos, promessas apaixonadas e juras de amor... como em qualquer pedido público de casamento entre pessoas que se amam e que já se namoram há muito tempo! Além das cenas, o que talvez chame mais a atenção são as reações em simultâneo das crianças, seguidas de seus surpreendentes comentários. A concepção do vídeo dentro do vídeo (crianças reagindo em takes sobrepostos às sequências de pedidos de casamento) é didaticamente interessante para a nossa proposta; tendo em vista que, dessa forma, as/os estudantes podem - de maneira mais desinibida - também manifestar as suas opiniões e pontos de vista. Na prática, a intermediação dos comentários das crianças faz com que os/as estudantes transfiram, não diretamente sobre os casais que protagonizam as cenas, mas secundados/as pelas crianças, a emissão de suas impressões e juízos de valor.

Sabemos que as crianças são espontâneas e verdadeiras. Elas estão ali, naquela experiência, como filtros de sinceridade: livremente emitindo as suas impressões, opiniões e comentários. Essa espontaneidade arrefece, desarma as resistências dos/as alunos/as em tratar da temática; servindo como uma espécie de estímulo didático, em anteparo à reflexão e à participação no debate. O espelhamento da participação das crianças no vídeo é, portanto, estratégico para a desinibição. $\mathrm{O}$ fato de essas crianças emitirem opiniões e comentários divergentes traz igualmente para a proposta o necessário contraditório. Em razão de a faixa etária das crianças ser ligeiramente inferior à dos/as estudantes, há ainda a expectativa de que estes/as últimos/as melhorem/aprofundem/comentem e mesmo retifiquem as reações e opiniões dos/as pequenos/as que estão participando da experiência.

Espera-se do brainstorming e do debate, ante o conteúdo exibido e legendado em inglês, a familiarização de palavras e expressões como gay, lesbian, queer, gender, straight, hiding, coming out, same sex-marriage, proposal, weird, normal, same right, love e freedom ${ }^{\mathrm{ix}}$ : as quais são consideradas chave para a articulação das discussões de gênero. Ainda conforme esse intuito, a fim de previamente se diagnosticar a apropriação semântica das/os estudantes quanto a essas expressões, é que se sugere a construção coletiva do brainstorming - nos minutos que antecedem a exibição do vídeo -: o que também serve como introdução a possíveis outras Revista Interinstitucional Artes de Educar. Rio de Janeiro, V. 7, N. 1 - pág. 293-314 janeiroabril de 2021: "Pedagogias Vitais: Corpo, Desejo e Educação" DOI: 10.12957/riae.2021.54781 
práticas de escrita e oralidade (MALLMANN, 2019). Essa proposta metodológica do brainstorming - como icebreaker - intenciona, em paralelo, a preparação e a desinibição das/os estudantes diante do conteúdo, colaborando na redução dos possíveis entraves comunicativos (MALLMANN, 2019). Depois da apresentação das cenas e das reações, há uma seção no vídeo (question time) em que o entrevistador faz as seguintes perguntas às crianças:

O que aconteceu em ambos os vídeos? Como você se sentiu com os vídeos? Você acha que gay é algo bom ou ruim? Por quê? Qual você acha que foi a reação das pessoas quando assistiram essas cenas? O que você acha das pessoas que ficam bravas com propostas de casamento gay? Você sabe o que é ser gay? Você sabe de onde vem a palavra gay? Por que algumas pessoas gostam do outro gênero e outras do mesmo gênero? Você acha que as pessoas nascem heterossexuais ou gays? É possível transformar gays em heterossexuais? O que você acha do casamento gay? Você sabe por que algumas pessoas não gostam do casamento gay? Em alguns países do mundo você pode ser preso/a se for gay, e em outros, pior, você pode até ser condenado/a à morte. $\mathrm{O}$ que você acha disso? Por que você acha que é tão interessante para outras pessoas saber quem você ama ou com quem vai se casar? Por que a maioria dos/as gays ainda tem medo de se assumir? E se o/a seu/sua melhor amigo/a dissesse que ela ou ele é gay, como você reagiria? Quais são as causas relevantes para se ser contra o casamento gay? O que você diria às pessoas que acreditam que o casamento gay não deve ser permitido? O que você diria a um/a amigo/a gay que agora está lutando para se assumir? Você acha que algum dia o casamento gay será permitido em todos os lugares? Por que direitos iguais para todas as pessoas é algo tão importante? (FBE, 2013, 3'36"-15'55'. Disponível em: https://www.youtube.com/watch?v=8TJxnYgP6D8\&t=649s. Acesso em 15 de set. 2020. Transcrição e tradução nossas).

Depois de assistirem as respostas e argumentações das crianças, a ideia é propor essas mesmas questões também para os/as estudantes. Inicialmente em um fórum e, depois - caso flua bem a discussão -, em um debate aberto. Almeja-se com isso evidenciar os modos como nos posicionamos e somos posicionados/as nos discursos: em relação às diferentes percepções e opiniões a respeito da diversidade sexual e do casamento entre pessoas do mesmo gênero. Para além da apropriação discursiva dos direitos humanos e das diversidades, o objetivo é também o de analisar como as evidenciações e percepções de ódios e preconceitos se apresentam nos discursos, fora e dentro da sala de aula. Pretende-se isso mediante o exercício dialógico e linguístico-discursivo de construção de algumas argumentações, formuladas em sentenças e opiniões emitidas em língua inglesa (MOITA LOPES, 2002, p. 192). 


\section{Considerações finais}

Os maiores desafios da educação atual não se detêm no alcance ou na superação externa de fatores técnicos/tecnológicos, mas na possibilidade de se produzir conhecimento para a conscientização e humanização da vida: sobretudo daquelas/es que mais sofrem às margens das dinâmicas de exclusão social. As aulas de língua inglesa podem, nesse sentido, contribuir de modo mais efetivo na formação de nossas/os estudantes; especificamente no que, a partir de seu escopo comunicativo, fomentem discussões e debates como realizações ou plataformas de questionamento reflexivo às práticas de reprodução de injustiças e desigualdades.

No contexto da escola, em dinâmicas discursivas interculturais, interdisciplinares, plurilinguísticas, multiétnicas e engajadas com a promoção da igualdade - em defesa da vida e autodeterminação das pessoas! - essas aulas hão de contribuir, mais e melhor, para a formação cidadã, humanística e crítica dos/as estudantes. Potencializar relações temáticas entre o local e o global, por meio de produções e compreensões discursivas menos aprisionadoras e preconceituosas, notadamente a respeito das questões de gênero e diversidade sexual, é igualmente importante: para a resistência e oposição àquilo que ainda causa tanto sofrimento a corpos e performances deslegitimados por ódios e opressões sociais.

Entendemos que, ao mesmo tempo em que se deve acionar e desenvolver o instrumento comunicativo da língua inglesa com o mundo, importa igualmente fortalecer as relações e redes locais de formação: por meio da denúncia e enfrentamento às violências de gênero; assim como das demais supressões e opressões contra todas/os que ainda lutam pela autodeterminação de seus corpos, vidas, liberdades e identidades. É assim que a proposição das atividades deve ser planejada e realizada: de modo a considerar e oportunizar a desconstrução de estereótipos, discriminações e violências; em sinergia com a dinamização dos conteúdos e exercícios linguísticos: para além das meras reproduções de códigos e estruturas formais. Isso tudo a fim de que lhes sejam - às/aos estudantes - concedidas oportunidades reais de (re)ver, (re)pensar e (re)avaliar os lugares da diversidade; incorporando em suas consciências, pensamentos e discursos mais criticidade, sensibilidade, solidariedade e participação política.

\section{REFERÊNCIAS}

ANDRADE, Luma Nogueira de. Travestis na escola: assujeitamento e resistência à ordem normativa. Rio de Janeiro: Metanoia, 2015. 
BEAUVOIR, S. O Segundo Sexo, fatos e mitos. Tradução de Sérgio Milliet. São Paulo: DIFEL, 1970.

BENEVIDES, B.; SIMPSON, K. Mapa dos assassinatos de travestis e transexuais no Brasil em 2017. Associação Nacional de Travestis e Transexuais - ANTRA, jan, 2018.

BENTO, Berenice. Na escola se aprende que a diferença faz a diferença. Revista Estudos Feministas, v. 19, n. 2, p. 549-559, 2011.

BRASIL. Base Nacional Comum Curricular. Brasília: MEC, 2017. Disponível em: http://basenacionalcomum.mec.gov.br/images/BNC C_20dez_site.pdf. Acesso em: 15 de set. 2020.

BUTLER, J. Problemas de Gênero: Feminismo e Subversão da Identidade. Rio de Janeiro: Civilização Brasileira, 2010.

COLLING, Leandro. Gênero e sexualidade na atualidade. Salvador: EdUFBA, 2018.

FBE. I. (03 de nov. de 2013). 01 vídeo (15'58'’). Kids react to gay marriage. Acesso em 15 de set. 2020. Publicado pelo canal Kids react. Disponível em: https://www.youtube.com/watch?v=8TJxnYgP6D8\&t=649s.

FURLANI, J. Encarar o Desafio da Educação Sexual na Escola. Paraná. Secretaria de Estado da Educação. Superintendência de Educação. Departamento da Diversidade. Núcleo de Gênero e Diversidade Sexual. Curitiba: SEED- PR, 2013, p. 37-48.

LOURO, G. L. Gênero, Sexualidade e Educação. Uma perspectiva Pós-Estruturalista. Petrópolis: Vozes, 1997.

Pedagogias da Sexualidade. In: LOURO, G. L. O corpo educado, pedagogias da sexualidade. 2. Ed. Belo Horizonte: Editora Autêntica, 2000, p. 07-26.

Currículo, Gênero e Sexualidade: o "normal", o "diferente" e o "excêntrico". In: LOURO, G. L; FELIPE, J.; GOELLNER, S. V. (Orgs.). Corpo, Gênero e Sexualidade: um Debate Contemporâneo na Educação. 9. Ed. Petrópolis: Vozes, 2013.

MALLMANN, Mariana Taís. A BNCC na prática: o ensino de língua inglesa pautado por projetos pedagógicos. 2019. 57 f. Trabalho de Conclusão de Curso (Curso de Letras). Univates. Lajeado, 2019.

MISKOLCI, Richard. Teoria Queer: um aprendizado pelas diferenças. São Paulo: Autêntica, 2017.

MOITA LOPES, L. P. da. Identidades Fragmentadas: a Construção Discursiva de Raça, Gênero e Sexualidade em Sala de Aula. Campinas: Mercado das Letras, 2002.

Socioconstrucionismo: Discurso e Identidade Social. In: MOITA LOPES, L. P. (Org.) Discursos de Identidades: discurso como espaço de construção de gênero, sexualidade, raça, idade e profissão na escola e na família. Campinas, SP: Mercado de Letras, 2003. 
Linguística aplicada e vida contemporânea: problematização dos construtos que têm orientado a pesquisa. In: MOITA LOPES, L. P. (Org.). Por uma Linguística INdiciplinar. Parábola Editorial, 2006, p. 85-107.

Linguagem e escola na construção de quem somos. In: FERREIRA, A. de J. (Org.). Identidades sociais de raça, etnia e sexualidade - práticas pedagógicas em sala de aula de línguas e formação de professores/as. Campinas, SP. Pontes editores, 2012.

OLIVEIRA, J. M. D. Mortes violentas de LGBT+ no Brasil - 2019: Relatório do Grupo Gay da Bahia. $1^{a}$ ed. Salvador: Editora Grupo Gay da Bahia, 2020, p. 16.

PENNYCOOK, A. Uma Linguística aplicada transgressiva. In: MOITA LOPES, L. P. da. (Org.) Por uma Linguística Aplicada INdisciplinar. São Paulo: Parábola Editorial, 2006, p. 6783.

PINTO, J. P. Gênero e suas articulações para igualdade e pluralidade na Educação Linguística. In: FERREIRA, A. de J.; JOVINO, I. da S.; SALEH, Pascoalina B. de O. (Orgs.) Um olhar interdisciplinar acerca de Identidades Sociais de Raça, Gênero e Sexualidade. Campinas, SP: Pontes editores, 2014, p. 103-122.

TEIXEIRA-FILHO, F. S.; RONDINI, C. A. Ideações e tentativas de suicídio em adolescentes com práticas sexuais hetero e homoeróticas. Saúde e Sociedade, v. 21, p. 651-667, 2012.

\footnotetext{
${ }^{\text {i }}$ Professor de Filosofia do Instituto de Humanidades/IH e do Programa de Pós-graduação Interdisciplinar em Humanidades/POSIH da Universidade da Integração Internacional da Lusofonia Afro-brasileira/UNILAB - Ceará, Brasil. Ex-Professor de Inglês da Associação dos Professores do Ensino Superior do Estado do Ceará, APESC Ceará, Brasil. ORCID iDhttps://orcid.org/0000-0003-0474-7331.

ii Bacharel em Humanidades e Graduando em Licenciatura Plena em História pela Universidade da Integração Internacional da Lusofonia Afro-Brasileira/UNILAB - Ceará, Brasil. Atualmente é Professor de Inglês da Rede Municipal de Ensino da Prefeitura de Palmácia- Ceará. Realiza pesquisas sobre o Ensino de Língua Inglesa; Formação de Professores; Gênero, sexualidades e Educação. ORCID iDhttps://orcid.org/0000-0002-2207-6896.

iii Conferir, a respeito da propagação das violências transfóbicas, o mapa dos assassinatos de travestis e pessoas transexuais no Brasil, elaborado pela Associação Nacional de Travestis e Transexuais (ANTRA), em parceria com o Observatório da Saúde LGBT e com o Centro de Estudos Avançados Multidisciplinares da Universidade de Brasília (CEAM/UnB), disponível em: https://antrabrasil.files.wordpress.com/2018/01/relatc3b3rio-mapa-dosassassinatos-2017-antra6.pdf. Acesso em 13 de set. 2020.

iv De acordo com Teixeira-Filho e Rondini (2012), a quantidade de adolescentes LGBTQIA+, com idades entre 12 e 20 anos, de todos os níveis e estratos sociais, que apresenta ideações e tentativas de suicídio pode ser até cinco vezes maior do que a dos/as demais que se identificam como heterossexuais. Também foi observado, nessa mesma faixa etária, que a depressão e o uso de drogas tendem a ser significativamente mais expressivos entre pessoas LGBTQIA+. A pesquisa verifica ainda que a maioria desses/as adolescentes e jovens LGBTQIA+ - que idealiza, tenta ou consuma suicídio - sofre/sofria ou de distonias heterocentradas, negações e LGBTfobias internalizadas ou é/era propriamente alvo de agressões, violências e perseguições LGBTfóbicas, em contextos familiares e institucionais. A maioria revela ainda que o espaço escolar é bastante carregado de posicionamentos discursivos hostis e de práticas abertamente discriminatórias contra as suas sexualidades e identidades de gênero (trans ou queer). Os autores constatam haver uma verdadeira epidemia suicida entre a população de adolescentes e jovens LGBTQIA+ no Brasil, algo a ser encarado e tratado, por meio da abordagem de políticas específicas, como um problema de saúde pública, a fim de que a prevenção seja eficaz. Ainda de acordo com a pesquisa, é demonstrado
} 
que esses/as jovens recusados/as pela família abandonam até seis vezes mais a escola do que os/as que se autodeclaram heterossexuais, além de correrem até oito vezes mais risco de depressão e de outros transtornos psíquico-emocionais. Outra estatística chocante apontada pelo estudo é a de que um de cada doze jovens LGBTQIA+, entre 15 e 29 anos, já idealizou ou já tentou se matar. Disponível em: https://www.scielo.br/scielo.php?script=sci_arttext\&pid=S0104-12902012000300011. Acesso em 14 de set. 2020.

${ }^{v}$ https://www.youtube.com/user/React/about -. Acesso em: 15 de set. 2020

vi https://www.youtube.com/watch?v=7tUks1u8MdY\&t=5s. 10'09', Acesso em: 15 de set. 2020

${ }^{\text {vii }}$ https://www.youtube.com/watch?v=Jwwg1Yt18vE. 12'. Acesso em: 15 de set. 2020

viii (https://www.youtube.com/watch?v=8TJxnYgP6D8\&t=612s. 15'58', Acesso em: 15 de set. 2020)

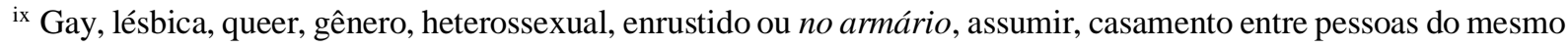
sexo, pedido de casamento, estranho, normal, direito igual, amor, liberdade. Tradução nossa. 